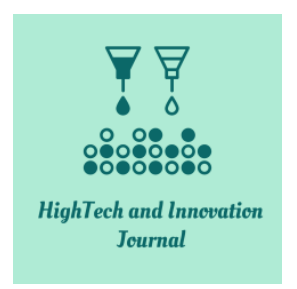

\title{
Challenges and Risks in the Due Diligence Process Answered with an Innovative Approach
}

\author{
Christoph Müller ${ }^{\mathrm{a}, \mathrm{b}^{*}}$ \\ ${ }^{a}$ Vysoka Skola Manazmentu / City University of Seattle Programs, Trenčin, Slovakia. \\ ${ }^{b}$ Aschenhausweg 2/3, 74523 Schwaebisch Hall, Germany.
}

Received 05 September 2020; Revised 08 November 2020; Accepted 14 November 2020; Published 01 March 2021

\begin{abstract}
In existing academic studies on the Due Diligence process, the different areas have been considered separately. This is time-consuming and causes inefficiencies. The proposed approach to Due Diligence integrates these separate areas into one process. While every company's success can be defined by a few key factors, these differ by industry. The goal of this analysis is to develop a basis for decision-making regarding Mergers and Acquisitions for small- and medium-sized manufacturing companies. It also has a positive impact on the success rate of mergers and acquisition transactions by generating a scorecard model that enables the potential acquirer to perform an overall analysis of the existing data as well as to generate an informed outlook for the future using a standardized and efficient approach. The model is based on different research methods. First of all, a literature research was conducted to define the theoretical framework. There are two main areas, the Strategic Controlling on the one hand, and M\&A, on the other hand. The theoretical findings are specified through expert interviews. The expert interviews are semi-standardized. There is a quantitative and a qualitative part. Based on the analysis, a concept for a leaner DD approach has been developed. The article presents a summary of the research.
\end{abstract}

Keywords: Mergers and Acquisition; Due Diligence; Strategic Controlling; Integrated Analysis; New Approach for Company Evaluation; Synchronization of Controlling in Pre- and Post-merger Phase.

\section{Introduction}

There are various approaches to company growth. Organic growth based on the gain or recovery of market share is a possibility, as is the development of new markets and the acquisition of competitors or complementary companies. Depending on time, market, and company, the right approach needs to be chosen. In the past, Mergers and Acquisitions (M\&A) were more likely executed by multinational companies, but nowadays the number of transactions involving mid-size companies is growing steadily [1]. In addition to the above-mentioned background, there are still two specific approaches for smaller companies for a vertical or horizontal expansion. On the one hand, the negotiating power with regard to customers and suppliers increases as a result of the increase in volumes. On the other hand, small and mid-size enterprises (SMEs) all around the globe are facing the challenge of not having a successor for the company. According to statistical assessments, only in Germany, there will be a lack of up to 110,000 company follow-ups over the next five years [2]. While big companies have easier access to resources to run an M\&A process, for example with an own department, SME mostly do not have M\&A know-how and resources available. But even big companies that seem to have the right resources, are not seldom in a state of economic problems after the takeover. Sometimes the whole transaction is being completely cancelled.

* Corresponding author: christoph.mueller.msc@gmail.com

doi) http://dx.doi.org/10.28991/HIJ-2021-02-01-06

$>$ This is an open access article under the CC-BY license (https://creativecommons.org/licenses/by/4.0/).

(C) Authors retain all copyrights. 
The question is: What is the reason for that? And what could be done different to avoid the inefficiency?

M\&As are based on a thorough examination of the so-called "Due Diligence" (DD) [3]. In the process of DD, the acquisition target is typically split into different sub-areas, and each one is analyzed using a separate checklist to ensure that the essential points at each level are considered, analyzed, and audited. Based on existing studies, an average of 183 man-days are needed for a DD. In big companies, entire departments are entrusted with this process. In small companies, however, M\&A departments do not exist as resources are smaller and limited. Due to that, SMEs often involve external partners to provide the missing expertise and capacity. A disadvantage to this approach is that external partners may lack industry specific knowledge. Therefore, the ability to assess the findings and draw the correct conclusions is limited for SMEs due to limitations in time, resources, and experience [1].

Overall, conducting an in-depth review is a big challenge; assessments of the future performance of the potential acquisition over a brief period are particularly difficult. This is why to a large extent, issues arising after an acquisition are attributable to errors that occur in the DD process due to time constraints [4].

This article hypothesizes that a new DD approach could help to increase the efficiency and the quality of the DD process and its recommendation in regards of the potential M\&A.

\section{Research Methodology}

Different research approaches were evaluated in preparation of this article. The most appropriate ones were finally chosen. The first part is of theoretical nature and was executed by analyzing the existing literature. The theories behind M\&A and DD are evaluated as well as the Controlling approach using the scorecard model. As part of the literature review an introduction of the most important terms can be found in chapter three of this article. Furthermore, empiric research is executed. Qualitative and quantitative methods were analyzed. The main goal was to get more detailed information about the theoretical findings. Finally, the method expert interview was chosen. The structure of the interviews is described in chapter four. Based on the theoretical background and the information gained out of the expert interviews the challenges and opportunities are analyzed. A summarized version is shown in chapter five. Based on the findings a new DD approach is defined on a conceptual basis. The concept will be introduced in chapter six. In the ongoing research a case study will be used as proof of the concept. The case study is part of the research, but not of the article. The following figure illustrates the research method.

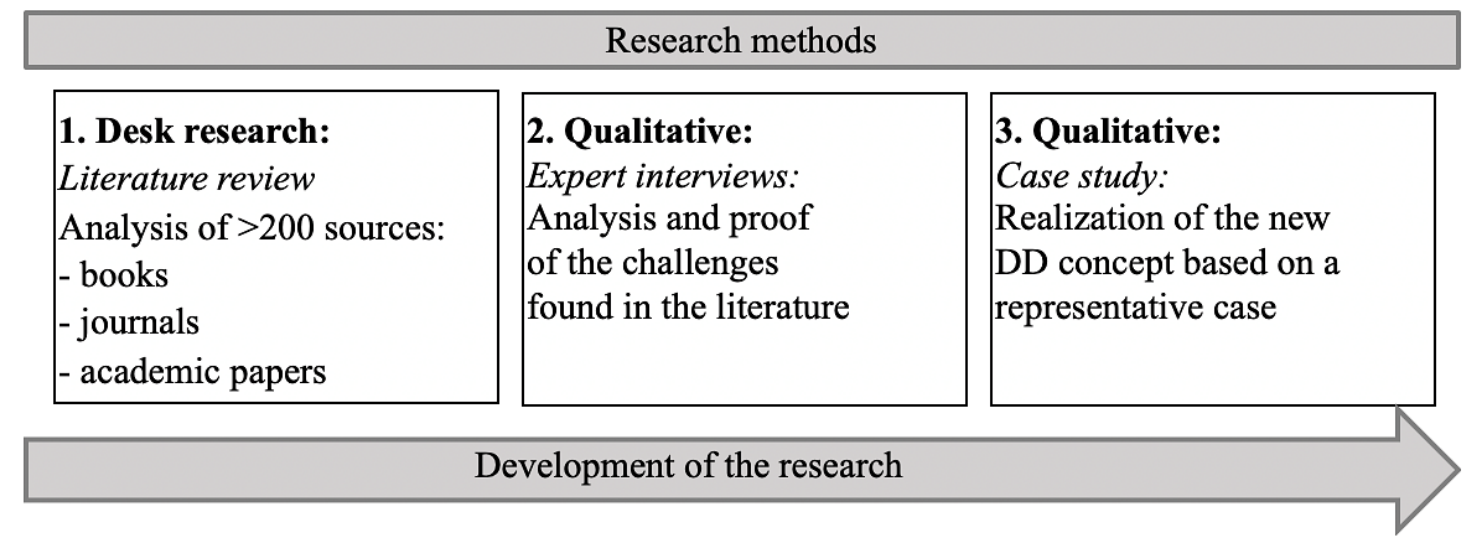

Figure 1. Research methods

The literature review approach was chosen as the best approach to desk research. It provides an essential basis for further research and it comprehensively summarizes the existing research on the topic [5]. As part of the process, the entire theory behind the M\&A process was defined. This begins with a description of the variations of entrepreneurial cooperation. The theory defines a wide spread of options, from strategic alliances up to full-mergers [6]. In the next step the M\&A process was investigated with specific focus on the DD sub-area [7]. The last research area was on strategic $\mathrm{CO}$, which creates the interface between the M\&A transaction and the regular CO of a company. The scope was set and analyzed in detail. Overall, the topic was divided into three major clusters: entrepreneurial cooperation, DD and strategic CO. In order to get a 360-degree view on the topic, books, journals and academic papers were considered. In total more than 200 sources were evaluated.

Based on the thorough desk research, a qualitative research technique was used to obtain more detailed information: the expert interview. Expert interviews are used to gather knowledge and a better understanding of an actual situation, based on an interview framework specifically developed to facilitate the interview [8]. This approach was used to gain a better understanding of the challenges of companies during the M\&A process and in particular during DD. Detailed questions about completed DDs were asked to get a better understanding of their content and how they are executed. Besides that, it also offered the possibility to gain information about opportunities to improve the 
process. The interviews were anonymized to gather input from more participants, in different areas. Those who were willing to share their experiences and to describe the challenges as well as suggestions for improvement are the most desirable interviewees [5].

The third chosen research method was case study. In the sense of qualitative empirical social research, a case study is a complex research approach. Qualitative research methods in general and case studies in particular have gained increasing popularity at the international level of research in the last decades. Outstanding work that have made substantial contributions to progress and innovation in the economic and social sciences has been of a qualitative nature, e. g., Porter 1991, Kaplan and Norton 1996, Ghoshal and Bartlett 1990, Mintzberg 1979. The work of these researchers mentioned has helped to improve the reputation of qualitative research in business and economics. Qualitative research methods, and especially case study research, should be seen and understood as what they really are, a useful and necessary complement on an equal footing with economic models and quantitative research. Case studies have strengths that compensate the shortage of the other methods. Indeed, case studies offer advantages that are lacking in other methods. With case studies, researchers can perceive complex relationships in their overall context, and case studies involving novel or rare phenomena can be investigated in a timely manner. In short, quantitativelyoriented science frequently relies on case studies [9].

For the mentioned reasons the research focused on two qualitative research methods besides the desk research: the expert interview and the case study. In the following chapters, these outcome will be explained.

\section{Desk Research}

First, it was important to get a better understanding of the existing concepts in the research context. This was done through a desk research. Desk research is a secondary research approach that entails gathering, processing and interpretation of existing data without own collection of the same [3]. Before starting the research, the scope was set. This was done based on the company lifetime. The most relevant aspects were defined. Based on the problem description, the M\&A process and the strategic $\mathrm{CO}$, were identified as the central theories for the investigation.

\subsection{Mergers and Acquisitions}

Companies choose M\&A, in particular in the same or related industries, when they want to strengthen their core business [10]. On the other hand, companies are selling their non-core businesses. Both reflect the optimizing strategies of companies, which face increasing challenges [11]. This includes the acquisition of a competitive advantage. Especially when it comes to different technologies needed in different markets companies try to assure access to the relevant products to have the power over the quality and price of these products and related innovation [12].

First of all, the decision of a company is made to participate in a M\&A transaction because a potential target, which was identified to be beneficial to its strategy. There are different approaches in literature, but the majority of it claims that a merger follows the three following phases:

- Pre-merger phase;

- Merger- or transaction phase;

- Post-merger phase.

The three phases are the main steps within an M\&A process and can therefore be broken done in sub-areas. Concepts with up to nine phases are existing [13]. Out of all different theories a common understanding is that an acquisition consists of screening, selection, evaluation, pricing, negotiation, DD, closing and integration [14].

Screening, selection and evaluation can be interpreted as the pre-merger phase [13]. This phase includes an analysis of the company followed by an analysis of the competition and the market. The evaluation of the motive for the merger delivers the definition for the strategies of the acquisition [14]. The merger or transaction phase starts with contacting the possible target and to start negotiations followed by the DD and the closing. The DD process carefully analyses the to be acquired company on different sub areas, such as economic, legal, tax and financial circumstances [13].

The post-merger phase includes a post-merger planning and ends with a post-merger audit which concludes the M\&A process [13]. An additional topic, which needs to be included as well is the post-merger-integration (PMI) [14]. Usually there is no difference made between the M\&A process of Large-Scale Enterprises (LSEs) and SME. In other words, the process of M\&A is the same, even the organizational structure and the available resources and the knowhow regarding M\&A are significantly different. The following illustration visualizes the three main and nine sub areas of the M\&A process in its consecutive order. 


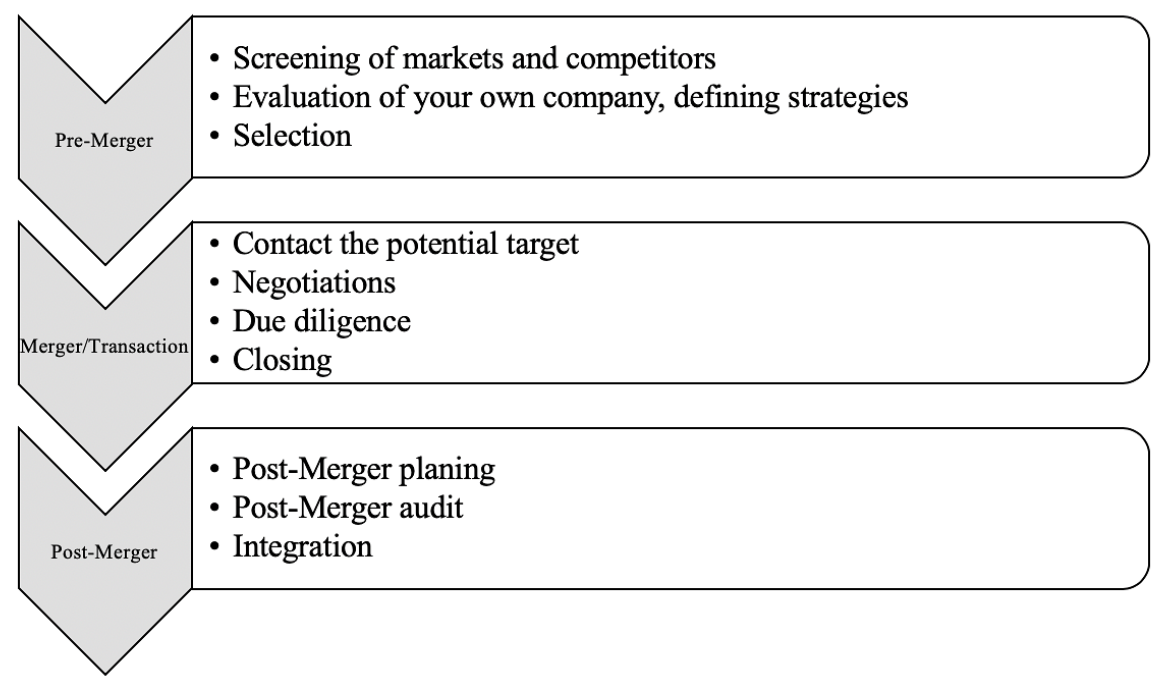

Figure 2. M\&A process

Every single phase offers room for improvement and can be optimized. The focus of the research is on the DD area as the key for a successful M\&A.

\subsection{Due Diligence}

There is not one overall valid definition of DD in the existing literature. It can be described as a detailed examination of a company, executed before becoming involved in a business arrangement with it, such as buying or selling its shares [15]. It is the investigation with a reasonable standard of care [1]. Further specified is the careful analysis and valuation of an object in a business transaction [16]. Concept and wording were created and established in the United Stated of America as part of the security laws and is nowadays used, with the English expression all around the globe [17]. In other words, DD is the basis for M\&A. It is a thorough examination of another company [18].

The capacity of the company's internal assessment of the findings and the drawing of the correct conclusion are often limited due to a lack of time and experience. In big companies, whole departments are entrusted with the DD in the context of company acquisitions. SME often involve external partners to cover the missing experience and capacity [1]. Although business transitions in the same country are already complex under the same legal conditions as well as under identical accounting rules, the complexity of the transitions in an international context is multiplied by a large number [19].

As a basis of the DD the company to be examined is split into different subdivisions. Each of it is carried out with separate checklists to ensure that the essential points at each level have been subjected, analyzed and audited. It does not primarily refer to the components and circumstance of the test but to the quality of the tested components [20]. Initially, the main components were financial, tax, legal, commercial, organizational and technical DD. Due to developing markets and the differences between industries the number and the content of DD can be different [21]. The reasons for a DD are diverse and range from the departure of a shareholder, on to the transformation of the company form. Other reasons can be the follow up with a turnaround of an enterprise after its recovery and the final sale of the company [19]. The basic structure is further subdivided and adjusted depending on the reasons and the resulting focus of the audit. Depending on the scope of the test, a distinction is made between full and partial DD. When buying a company, a fully comprehensive audit is performed, which also has a high level of detail [19]. The main requirement is to recognize the opportunities and risks of a company purchase in advance and thereby to prepare the fundamental decision regarding a company purchase [1].

It is the goal to conduct a complete and consistent assessment of the target company. All factors on the buy-side are used. This is the so-called buy-side DD. The counterpart is the sell-side DD, in which a company is judged from the seller's point of view. The goal is to evaluate all transactions that are responsible for the success of a company with a 360-degree view of the company [22].

\subsection{Strategic Controlling}

Behind company-wide, active controlling and active corporate management is much more than a cost control system. An integral part of company-wide integrated controlling is the commercial, technical, sales, market and environment-based controlling. Nowadays, controlling by means of detailed and constantly reviewed planning and simulations prevents wrong decisions and efficiency losses of all kinds. Companies gain access to transparent structures and procedures, from which improvement and cost-saving potentials as well as growth potentials can be 
identified. It is the crucial foundation for current and market-oriented corporate governance. In general, it helps to permanently improve results, to plan the success of individual departments in detail and to detect and eliminate weak points. Controlling and the associated business intelligence systems are a key factor in business success, regardless of size and global positioning. Kaplan and Norton understood the shortage and inefficiency of the classical Performance Measurement System (PMS) and created a model that had a more holistic view, which eliminated the problems of classical PMS. With the invention of the Balanced Scorecard (BSC), organizations focused on short- and long-term goals, monetary- and non-monetary indicators and perspectives of external and internal performances [23].

"The BSC complements financial measures of past performance with measures of the drivers of future performance. The objectives and measures of the scorecard are derived from an organization's vision and strategy." [24].

The ultimate goal of the BSC was to translate strategy and vision of an organization into measurable objectives. Those objectives can be subdivided into four different perspectives: Financial, customer, internal-business-process and learning and growth [25]. The expectations of the shareholders define the financial perspective. The customer perspective identifies how the organization wants to be seen by its customers. The internal-business-process perspective explains the business processes. The processes are important for the organization to satisfy the expectations of shareholders and customers. The learning and growth perspective shows the improvements and changes the organization needs to implement in order to translate vision into strategy. Kaplan and Norton encouraged managers to monitor Key Performance Indicators (KPI) of the four respective categories that picture a balanced view between short- and long-term goals, monetary- and non-monetary indicators, and a perspective of external and internal performance [23]. But all KPIs should be linked with financial goals, because if the employees are not satisfied with the new formed organization, their performance will not increase over time and hence the internal processes will not become leaner. Therefore, customer requirements cannot be processed in an appropriate time which can lead to unsatisfied customers. As a consequence, sales will drop, and this will impact the financial KPIs.

\subsection{Findings and Basis for Further Research}

The first result obtained from the literature review is that the three disciplines investigated, entrepreneurial cooperation, DD and strategic CO are all already well elaborated. Furthermore, they are all applicable in the company lifetime and there are as well sufficient practical examples, confirming the practicability of the theories.

Nevertheless, there is no direct link between them. The DD, which is especially considered as part of the M\&A process and the strategic $\mathrm{CO}$, are used independently from each other, even though they have an interface, as shown in the following illustration. The interface is defined to be either in the last step of the M\&A process, the PMI phase or after.

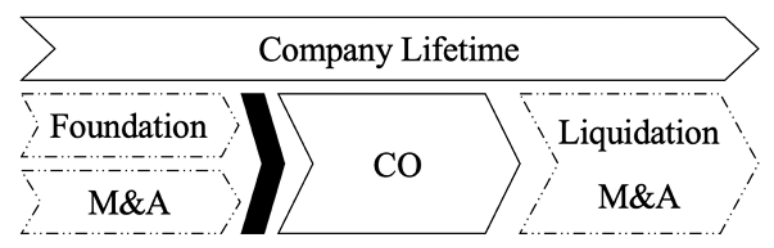

Interface

Figure 3. Theories applicable in the company lifetime

In consequence to these and based on other findings in the literature review it is assumed that the ultimate cause of the M\&A failure at the end could have possibly been discovered during the DD with a more integrated form of evaluation and a closer connection to the strategic $\mathrm{CO}$ of the company.

Because of the missing link between DD and strategic CO there are redundancies, which cause time constraints in the DD due to limited resources. The literature shows that to a large extent, problems arising as a result of company acquisition are related to time constraints in the DD.

Another finding was that the different sub-areas within the DD process have generally been considered detached from each other. All sub-areas of the DD process are described in detail and the importance of each area is well but separately highlighted. Within the CO, the BSC approach also divides and evaluates the company in different subareas; the organization in this context is however seen as an integrated system. This means the hierarchical dependencies are considered in strategic CO, while they are not in DD. 
DD

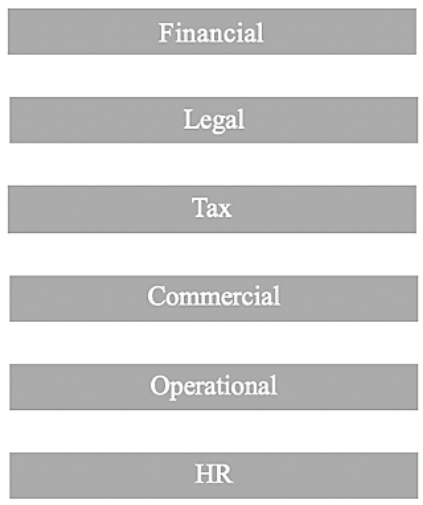

vs.

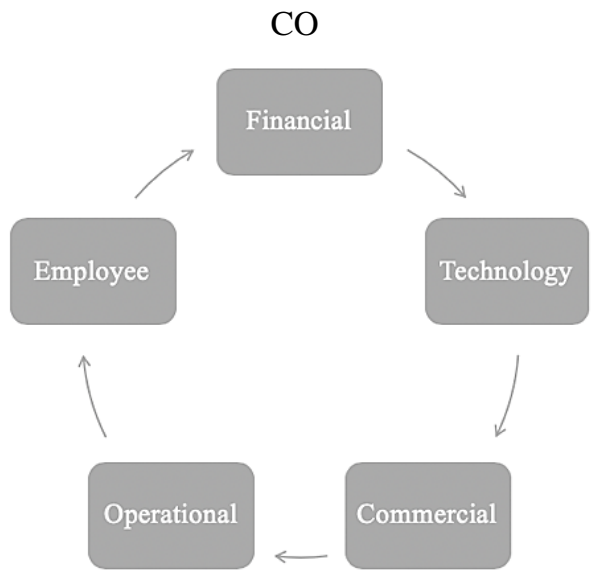

Figure 4. Integration of disciplines DD vs. CO

From the literature review, it was also shown that the disciplines have different time orientations. While the strategic $\mathrm{CO}$ covers the whole-time line, beginning with the past through the present and with a future orientation, the DD approaches are strongly oriented to the target company's present and past situations. The future orientation and the sustainability are not reflected to the same extent in the DD than as they are reflected in strategic CO. In other words, the sustainability, the future orientation and the future viability of the company remain largely ignored. DD represents only a static assessment of the actual situation. Strategic CO provides an outlook on the company's sustainable success potential.

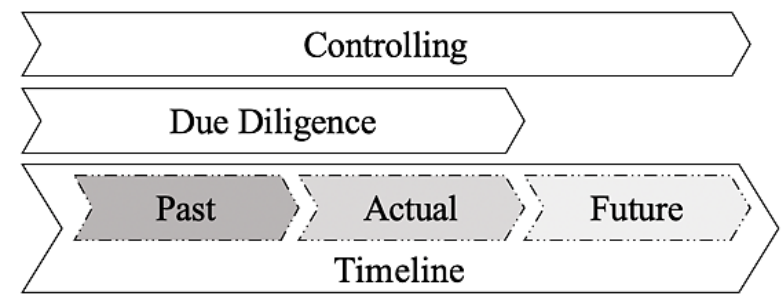

Figure 5. Timely focus of DD vs. CO

The DD areas cover all the functions of the company, but only the Financial area is measured in KPIs, while the other areas are evaluated in a rather qualitative way. Strategic CO intends to measure all areas with KPIs; either monetary or non-monetary ones. Besides that, strategic CO additionally includes industry-level parameters, which only partially exists in DD.

The participants of the different disciplines show an intersecting set, but there are as well differences. Strategic CO mainly uses internal resources, while in the DD, external players are also involved depending on the company size and the sub-area of the DD. This causes the effect that the results of the DD do match with general standards and KPIs but they do not necessarily address the company's individual KPIs.

In regards to research questions one and two, it can be said that DD and strategic CO are involved in the M\&A process. There is an actual interface between the theories, but it is not well elaborated in the literature.

The above written findings obtained from the literature review are summed up below:

- No connection between different theories (DD vs. strategic CO);

- No connection between DD sub-areas;

- DD and strategic CO focus on different time frames;

- Both DD and strategic CO have different participants;

- Results are presented different ways in DD and strategic CO (DD general vs. CO company specific).

\section{Definition of Further Research Methods}

Based on the existing theories and the defined research goals, different research methods were considered. This sub-chapter provides an overview of these methods and those that were identified as suitable for this dissertation are described, including a discussion of how they will be used. 
For the development of a scorecard model two research methods are suitable. For defining the cause-and-effect relations between different hierarchy levels, quantitative methods based on statistical analyses such as linear regression can be used. For defining the KPIs within strategic CO, an experimental study is a good approach to identify the KPIs as well as the variables that influence each KPI [26]. Defining the BSC and a detailed analysis of the scorecard model is beyond the scope of this dissertation.

A statistical analysis could be used to understand the challenges companies have during the DD process, but the information for the analysis would have to be generated from an observational study [27]. The challenge here is to gain sufficient access to companies and specific M\&A cases to have a representative database for the research. The population is critical, as the packaging machinery industry is a niche within the manufacturing industry, and the challenge is compounded by the fact that M\&A transactions are highly confidential.

A qualitative research technique used to obtain detailed information is the expert interview. Expert interviews can be used to gather knowledge and a better understanding of an actual situation, based on an interview framework specifically developed to facilitate the interview [28]. This approach can be used to gain a better understanding of the challenges of companies during the M\&A process and in particular during DD. Detailed questions about completed DDs could be used to get a better understanding of their content and how they are executed. Besides that, it would also offer the possibility to gain information about opportunities to improve the process. Anonymizing the interviews often allows researchers to gather input from more participants, in different areas. Those who are willing to share their experiences and to describe the challenges as well as suggestions for improvement are the most desirable interviewees.

Case studies in the sense of qualitative empirical social research are a complex research approach. Qualitative research methods in general and case studies in particular have gained increasing popularity at the international level of research in the last decades [29]. Outstanding work that have made substantial contributions to progress and innovation in the economic and social sciences has been of a qualitative nature, e. g., Porter 1991, Kaplan and Norton 1996, Ghoshal and Bartlett 1990, Mintzberg 1979. The work of these researchers mentioned has helped to improve the reputation of qualitative research in business and economics. Qualitative research methods, and especially case study research, should be seen and understood as what they really are, a useful and necessary complement on an equal footing with economic models and quantitative research. Case studies have strengths that compensate the shortage of the other methods. Indeed, case studies offer advantages that are lacking in other methods. With case studies, researchers can perceive complex relationships in their overall context, and case studies involving novel or rare phenomena can be investigated in a timely manner. In short, quantitatively-oriented science frequently relies on case studies [30].

The dissertation thesis focuses on two qualitative research methods: the expert interview and the case study. In the following chapters, these two approaches are explained and used for the research.

\section{Expert Interviews}

The expert interview is a special form of the semi-structured interview. The person interviewed is herein reduced to their expertise in the related topic. The status as an expert is related to the research topic and therefore represents a subjective view of the interviewer. Within the research the experts are either employees of the SMEs involved in the DD process or consultants working with SMEs in such kind of DD projects.

\subsection{Structure}

As non-standardized or semi-structured interviews are a mixture of open and closed questions, the answers are formulated in their own words. Therefore, topics the interviewer did not think of, prior to the interview might be covered [31].

The closed questions, do already offer predefined answers. The answers are based on the literature analysis. Besides that, the interviewees do always have the option to mention an additional point not covered in the predefined answers. The category is called others. If the category is chosen, it needs to be specified. The open questions did not include any kind of predefined answers. The target is, to get more insights and a broader knowledge out of the experience of the experts. The answers are coded to define categories [32].

The expert interviews were held in a semi-standardized way. There were some key questions and some eventual questions. The key questions were asked in every interview to keep the same structure. The eventual questions were only asked, in case a clarification was needed or in case the interview tended to leave the standardized direction [33]. The following graph shows the questionnaire. 
Questionnaire - Qualitative Research dissertation thesis

1. What are the main drivers for M\&A?

2. Which phase within the M\&A procedure is the most challenging one, out of your experience?

3. Which are the main reasons for a failing M\&A project?

4. Which DD areas are you executing?

5. Why is this phase so challenging? / How would you describe the main difficulty of the DD?

6. What is based on your expertise, the best approach for the labor setup of the DD?

7. Why is this approach the most appropriate one?

8. What are the biggest challenges in setting up the right DD team?

9. In which area is it required to work with external consultants?

10. Could you please rank the importance of external consultants based on the DD areas you are executing ( $5=$ very important, $1=$ not important $)$ ?

11. In which area is the expertise of own employees important?

12. Could you please rank the importance of internal experts based on the DD areas you are executing $(5=$ very important, $1=$ not important $)$ ?

13. Why is it so difficult to get access to the right data during the DD?

14. Out of your perspective is there a link between the different DD areas?

15. Are the different DD areas in the execution integrated in one approach?

16. What is your strategic controlling approach?

17. Out of your experience is there enough link between the companies strategic controlling approach and the areas considered in the DD?

18. Would a stronger connection help to increase the quality of the DD and the success of the M\&A activities?

19. Out of your experience is there enough future orientation and enough focus on the sustainability of the target company?

20. How can the DD process be improved to be more efficient, without a decrease in quality?

Figure 6. Questionnaire

The questionnaire follows one guideline. The guideline was slightly adapted depending on the fact, if the interview was held with an employee of the SME or with a consultant. The interviews are analyzed in a combined way. There is a deductive approach as well as an inductive one. The deductive codes which are analyzed based on the parameters found in the literature research are the basis, which is enriched with inductive parameters found directly in the interviews.

Within the study ten experts were interviewed during a period of a month to provide further inside into the topic. The number was not predefined. The interviews were stopped, once the saturation point was reached and no additional information could be gained anymore. The basic requirements for all experts were, that they have at least five years of working experience in strategic controlling of a company or consulting and participated in M\&A.

\subsection{Results}

The expert interviews had the objective to confirm the overall M\&A situation in the packaging machinery industry. Additionally, the goal of the section was to precisely explore the challenges experienced by the experts in the DD process based on the concrete challenges that were found in the literature review. Besides that, another goal was to understand the options available for DD improvement as part of the M\&A process based on the opinions of the experts.

The overall development of the market described in chapter one was confirmed by the experts. This confirms the increase in M\&A activity in the packaging machinery industry in Germany and the necessity to decrease time and cost while increasing the quality of the entire DD process.

The challenges and opportunities seen in the DD process were as follows: 
Through the expert interviews, it became clear that there is currently not sufficient link between the different DD areas and that there is most likely to be no link at all between the strategic CO approach and the DD process. The experts mentioned that they expect the M\&A success rate to be increased by integrating DD into the strategic CO approach of the acquirer and by evaluating the target company using the acquirer's CO approach.

The expert interviews furthermore confirmed that the future viability and the sustainability of the target company are not sufficiently considered in the DD process, as the DD is mainly backward oriented. The timeframe of the CO is expanded and there is a stronger focus on future viability.

SMEs of the packaging machinery industry are not PE firms. They do not grow primarily from M\&A activities. They are limited in knowledge and capacity regarding the DD process. Thus, external experts with their own standards of conducting DD have to be involved. Most SMEs follow the structures of the external experts. The problem is that these structures are not linked to SMEs internal strategic CO that is the basis for the PMI phase.

Another outcome of the expert interviews is that the team approach was the right method, but with a structure defined by the acquirer, not by external consultants. With the right mix of participants and clear targets and objectives, the requirements can be defined in a more transparent way. The assumption is that this could make the process leaner and more efficient in terms of time and cost.

The DD areas need to be separated into two general groups, quantitative and qualitative ones, where the qualitative areas are based on legal issues. This includes the Legal and the Tax DD. The external experts play the most important role in these areas. It needs to be considered that Legal and Tax also have quantitative aspects that affect other quantitative DD sub-areas even though they are qualitative areas. There is a cause-and-effect relationship between the different sub-areas. The quantitative areas are Financial, Commercial and Operational.

The qualitative DD areas are rarely measured based on KPIs, while in the quantitative areas, using KPIs is beneficial and can be done in the same way as in the PMI phase and in strategic CO. The quantitative areas should therefore mainly be covered with internal experts. The stronger alignment between strategic CO and the DD phase of the M\&A process supports the idea of using the company's individual KPIs in the DD process as well. This could contribute to the efficiency of the DD process due to the use of little time to interpret the result.

Overall, the outcome of the literature research and the findings, and the statements from of the expert interviews defined the challenges of the current DD process and made it clear that a new approach for the DD process is needed to improve the uncertainties of the existing one and to integrate potentials in the process that have not been considered so far. Based on the weaknesses identified in the literature review and confirmed by the experts together with the indications given by the experts, the concept for an integrated DD approach was developed. The model will be introduced in the next chapter.

\section{Innovative Due Diligence Approach}

Based on the information gained out of the theories and the qualitative research a new concept for DD will be defined.

The target is to generate a decision basis for the M\&A of a competing enterprise in the area of manufacturing SME by developing a scorecard model including KPIs and their relevant internal and or external benchmarks which enables the potential buyer an overall analysis of the actual data as well as an outlook to the future on a standardized and time efficient method [34]. The idea is to combine the structure of Strategic Controlling of a company in the PMI phase and the DD. A comprehensive, high-quality company evaluation is essential, taking the parameters of time and personnel into account. As mentioned above the outcome is, that the different areas of DD, such as legal, tax, financial, commercial, technical and environmental have mostly been separated from each other. The possible procedures have been described, and the problem areas in the individual areas have been pointed out [35]. The new development deals with the integration of the different levels and the holistic assessment. In other words, the different areas will be linked to each other. A company always needs to be seen as an integrated system. There are hierarchical dependencies between the areas examined during the DD, which must also be understood and assessed as such. The following figure is showing an example for dependencies within a company. 


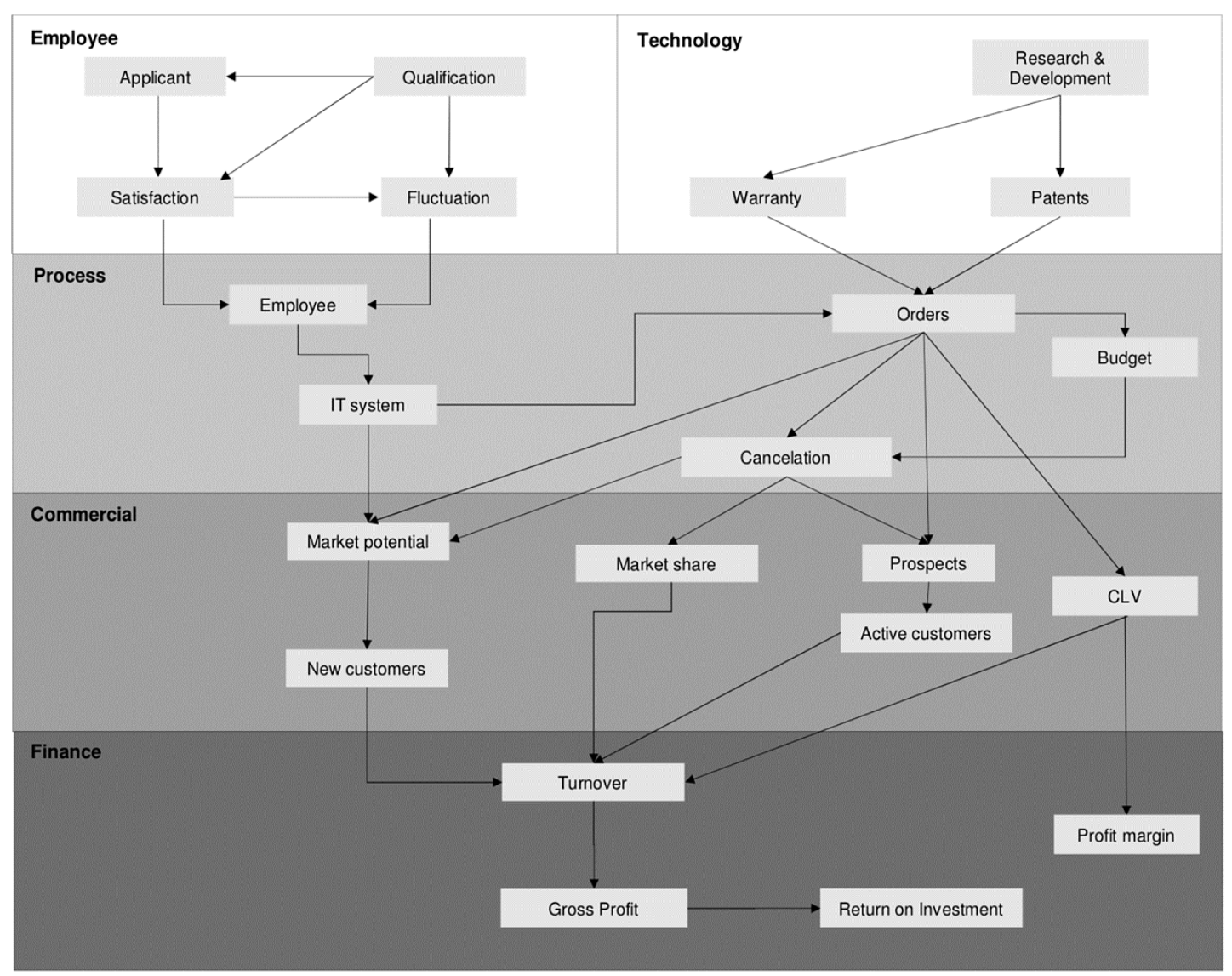

Figure 7. Dependencies within a company

The shown dependencies are the basis of a qualitative reasoning, which links the strategic targets of a company. It is difficult to define all connections, especially because the dependencies can go in both directions. But this is necessary to link the pre-existing checklists of the various DD through their interfaces, so that an integrated evaluation is possible [36].

For all the dependencies of the strategic targets in the company, the KPIs need to be defined to make the dependencies measurable. Commercial and technical levels for example are directly influencing the financial level of the company. The quality standard and the innovations of the products out of the technical area are influencing the commercial level. Quality for example can be measured by the costs for warranty. As an absolute value is difficult to compare, a ratio needs to be formed. A concrete ratio can be the warranty cost to turnover ratio. For the sustainability of the company innovations are important. The innovations can be measures in R\&D costs per turnover and total number of patents and their average time until expiry. In the next step the technological level is causing an effect on the process level, e. g. the orders by the customer. The quality of the order process can be measured in the order to quotation ratio. Furthermore, the cancelation-order ratio is giving a good indication for the connection and the dependency between the commercial part of the company and the technological one. Thinking about the financial level, the market share is a result out of the quality of the product and the sales process, in other words out of the technological and the process level. The market share as one part of the commercial area is influencing the turnover. If the market share is big, the turnover of the company is bigger and the power in the market is bigger as well. This has a direct influence on the gross profit and the result of the company.

Benchmarks, which depend on the individuality of the company, either from the market or from the company need to be taken into account. The experience and the existing knowledge as well as the resulting comparability of companies are greater in the case of acquisitions of competing companies than acquisitions of complementary companies up or down streaming the value chain. The new DD approach therefore relates to companies which are in direct competition with each other, which leads to the expansion of the market share [34].

In the figure shown below an example for a dashboard including some examples for the defined KPIs and an evaluation according their benchmark is displayed. While in the lower part the evaluation of commercial KPIs are shown, the upper part shows the financial level and a selection of its key figures. The indicators are shown in different ways, which allows the evaluating employee to get a fast overview and to do further research on the ones in a critical stage. 


\section{Employee}

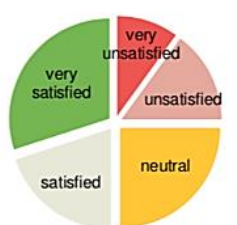

Satisfaction

\section{Technology}

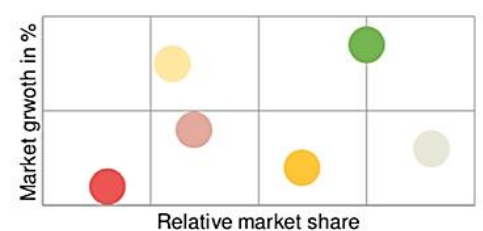

Patents

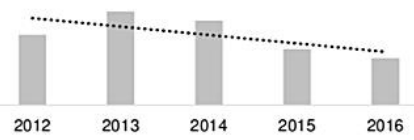

Fluctuation

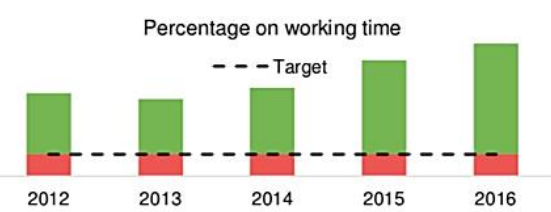

Qualification

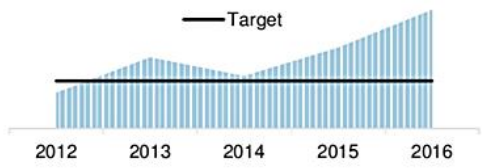

Research \& Development

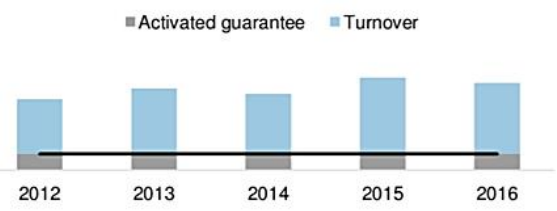

Warranty

\section{Process}

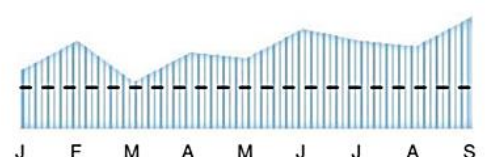

Orders

Commercial

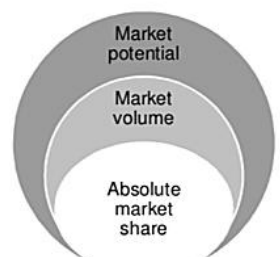

Market potential

Finance

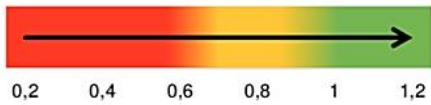

Gross Profit

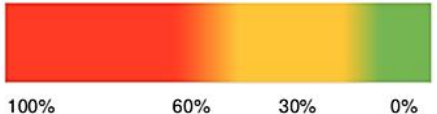

Cancelation

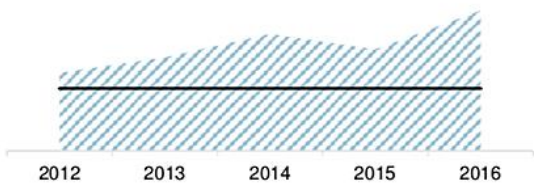

Budget

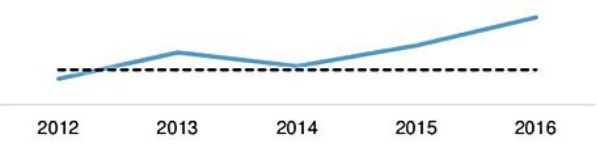

Customer Lifetime Value

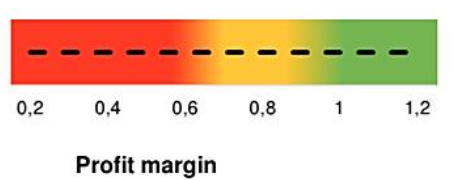

Figure 8. Mueller M\&A-Scorecard Model

A model for the integrated DD process, which is assessed by all company components both on the actual situation as well as on the future capability, can be represented on the basis of the prevailing theories. A challenge can be seen in the individual processes of a company and the different data quality. These must first be made comparable to the evaluation of the resulting key figures [34]. In the international environment the challenge to create a common data base is even bigger, due to legal differences, but once this goal is achieved with a structured procedure the created measures can be used in an efficient way to evaluate the company and to decide about starting the negotiations of the M\&A or to stop them on an early stage [36]. 


\section{Case Study}

Case studies have been a part of qualitative research since the 1960s. For a long time, case studies were not considered an appropriate research method in Business and Economics. The main criticism was that the population in case studies is too small and that the outcome could be influenced by the subjective view of the researcher. This has changed in recent decades [37], and case studies are now considered to be especially useful when trying to test theoretical models by using them in real-world situations. Analyzing results of a case study tends to be more opinionbased than with statistical-methods based. The implementation of case studies usually involves collecting data, putting it into a manageable form and constructing a narrative around it [38]. Even a single case study can be sufficient to explain a certain phenomenon, particularly those with critical or classic characteristics [39].

\subsection{Description of the Case}

The case describes a DD conducted within the packaging machinery industry. The DD was executed by a German SME within the industry. The target is also located in Europe and is a competitor of the potential acquirer. Both the acquirer and target company are among the leading companies in the industry. The first contact between the target company and the potential acquirer was made through an M\&A consultant on behalf of the target company. There were several reasons for the target company to seek a partner. First, the main shareholder in the founder's family wanted to sell due to the fact that there was no successor within the family. Furthermore, the company saw the need for growth as they had lost some market share and wanted to strengthen their market position but did not have the financial resources to do so. In addition, customers had made it clear that they wanted to source their products from one company, to reduce administrative overhead. The result was that the selling company contacted M\&A consultants to have them search for an appropriate partner. After sending basic information about the target to the potential acquirer and the potential acquirer expressed interest, a LoI and an NDA were signed by both parties, to prepare for the next steps in the M\&A process. This was the starting point of the DD effort.

\subsection{Recommendation Based on the New Concept}

The recommendation is based on the integrated approach in the new DD concept that covers the qualitative and the quantitative parameters measurable with KPIs. The evaluation of legal and tax issues shows, there were no dealbreakers; this means, the risks revealed through the analysis are manageable. The result was displayed with the traffic light logic. For that reason, the DD continued. Otherwise it would have stopped immediately after the Legal and the Tax DD. The impact of the risks marked with the yellow traffic light was quantified and therefore became part of the quantitative analysis, displayed with KPIs, especially in the Financial area. This was already one difference from the originally executed DD, where the risks were only to be mentioned, but not further evaluated.

In the quantitative part of the DD, the data base was made comparable with the structure of the buy-side's and the risks were considered as well. More important was the integrated evaluation of the sell-side. The results are shown as KPIs. The KPIs ended up in the dashboard. The dashboard above gave the recommendation to proceed with the M\&A process. Which means, the new DD approach showed a positive result. The decision in the original DD and the recommendation regarding the decision about the DD in the case study here are therefore different. While the previously executed DD showed a negative result and the M\&A process was stopped, the new DD concept shows a positive result and recommends continuing with the M\&A process.

The recommendation above is the result of the simulation of the new DD concept based on the case study. The question is, which one of the two recommendations is the right one? To prove the functionality of the new DD approach, further analysis was needed. First, the actual development of the target company after the original DD was reviewed. The results are described in the following sub-chapter. This should provide a first indication of the hypothesis on whether or not that the new concept leads to a quality increase.

At the end the concept as well as the result of the case study were presented to expert two, whose expertise was also used during the expert interviews. The reason why expert two was chosen is that he was the CFO of the potential acquirer by the time the original DD took place.

\subsection{Discussion of the Results of the Case Study}

As a final step of the case study, the results were discussed in a follow-up expert interview. First, the experience of experts was used in chapter four to gain more knowledge about the challenges and the opportunities in the M\&A process in general and the DD process in particular. Based on that, the new concept was defined and applied in a case study. To verify the concept and the results of the case study, the results were presented to expert two. Expert two was selected because he was actively involved in the original DD.

As an introduction, the results of the expert interviews were shown to set the basis for the subsequent explanation of the new DD concept, which is based on the literature review and the expert interviews. The original DD had already 
taken place some years ago. Therefore, the original case was briefly described before the results from the case study were presented as shown above.

Expert two sees the improvement within the new DD approach based on the challenges and the opportunities the experts described during the expert interviews. Furthermore, the results of the case study were approved. Based on the result of the original DD, the outcome of the new approach and the actual development of the company after the DD were discussed, the expert confirmed the benefit of the new DD concept. Besides that, the efficiency increase in time and cost was discussed. The expert sees an improvement here as well. The criticism that came up was about the population due to the application of only a single case study. The reasons and the rationale for choosing a qualitative research approach were explained again. Overall, the expert sees a positive contribution to the further development of the topic. This is particularly due to the fact that the number of DDs in the packaging machinery industry is expected to increase over the next years. Once there is a bigger base of applied examples in the packaging industry, expert two sees the opportunity to transfer the concept to other industries as well.

The next illustration sums up the results of the expert interview.

Table 1. Results of the follow-up interview

\begin{tabular}{|c|}
\hline PRO \\
\hline 1. Positive impact on quality \\
\hline 2. Efficiency increase in both, time and cost \\
\hline 3. Transferability to other industries \\
\hline CON \\
\hline 1. Population (single case study) \\
\hline
\end{tabular}

\section{Outlook for the Innovative Due Diligence Procedure}

The outcome of the dissertation thesis was a new DD approach that was developed using qualitative research methods. During the selection of the research methods, the concern was that using a quantitative method would focus on backward-oriented data rather than on generating a new concept. But qualitative research also clearly has its limitations. While in the expert interviews, the saturation point was reached and the results can therefore be seen as representative, a case study only provides evidence that the concept has worked in the single case.

Due to that, there is room for further research. After several DD efforts are conducted using the new concept by SMEs in the packaging machinery industry, a quantitative research effort would be desirable. With a broader database, the DD process could also be reviewed again by using the CPM method. With a bigger population the actual time used could be measured and the critical path could be identified. Furthermore, a detailed cost analysis would be possible. The actual costs for external and internal experts could be calculated. As a result, the time-cost optimum of the new DD concept could be calculated.

Another important topic would be to extend the model to international M\&A activities. Certain areas were cut from the dissertation due to the need to restrict the scope and due to resource limitations. The task of developing comparable data sets was discussed but the issue of reconciling financial statements that were prepared using different accounting standards deserves special focus. The same applies within the qualitative DD areas where Legal and Tax DD can involve different legal and tax rules from different countries. The cultural differences and the Cultural DD that comes along with it should also be addressed as an aspect of a multi-country DD process. It would be important to discuss whether this DD area is strictly qualitative or if there is a possibility of making this DD area measurable in a quantitative way.

What also deserves further discussion is the impact of harmonizing the strategic CO approach and DD procedures on PMI. Right now, the concept focuses on a leaner DD process. An important question would therefore be whether and how much this harmonization could also improve the PMI phase.

At the moment the concept is designed for competing companies in the packaging machinery industry. The concept can be easily extended to other industries considering that the KPIs would have to be adjusted and realizing that the concept in the first-place targets M\&As within a horizontal diversification. This offers room for the expansion of the concept for acquisitions targeting a vertical or lateral diversification.

Due to the increasing awareness of the environmental and the social responsibilities of companies, another factor that could be added in the model in the future is the ESG DD. However, before integrating it into the integrated DD concept, some further investigation in the ESG DD itself is recommended. At the moment, it is still a niche and even tough it is considered as being important, there is still no clear way of applying it in the DD process. 


\section{Conclusions}

As stated in the first section, the dissertation hypothesized that a new DD approach could help in increasing the quality and efficiency of the DD process and its recommendation in regards to potential M\&A.

To answer the research questions, three methods were used. The literature review in chapter two showed that DD and strategic $\mathrm{CO}$, the two main theories influencing M\&A transactions, are well elaborated, but they have not been considered together so far, even though there is a clear interface. Further research was done with this consideration and the awareness that the number of M\&A transactions will increase in the next few years and that the current state shows inefficiencies and a low success rate. The challenges in the M\&A process were confirmed through expert interviews, and potential for improvements was identified. Based on the outcome, a new DD concept was elaborated.

The new approach integrated DD with the company's strategic CO. In other words, it tends to evaluate the target company in the same way the company approaches this internally, although the M\&A target does not belong to the acquirer. Furthermore, the right mix of participants in the DD process is defined. The team approach is seen as the right method, but with a DD structure defined by the acquirer and not by external consultants. The new approach is not only retrospective but also strongly oriented toward the future. The timeframe has been expanded, and there is a stronger focus on future viability.

The DD areas need to be separated into two general groups, quantitative and qualitative ones. The stronger alignment between strategic $\mathrm{CO}$ and the DD phase of the M\&A process supports the use of the company's individual KPIs in the DD process as well, and that the results of both qualitative and quantitative areas are displayed with KPIs.

By establishing a standardized DD procedure, companies can gain in-house expertise regarding the DD process, making them less dependent on external consultants. This alone will decrease the cost of DD for the company. Furthermore, it is a concept that can be applied to different DD efforts as they arise in the future. Considering the scale effect, the one-time set-up cost pays off as the number of DD efforts increases. With the right mix of participants and clear targets and objectives, the requirements can be defined more clearly. This makes the process leaner and more efficient in terms of time and cost.

Overall, this new approach to DD will not only save time for the potential acquirer but for the potential seller as well. It makes the entire DD effort leaner and more efficient. Collaboration is improved, increasing the satisfaction of both parties involved. In every market, the players know each other, so M\&A activities are sensitive as the parties involved have different interests. A structured and transparent procedure helps the parties understand each other better. Ultimately, the atmosphere during the DD process improves so that it doesn't matter whether the merger finally happens or not, as long as the parameters are clear and understandable for everyone. This helps to increase the respect for and reputation of the potential acquirer. This information will be shared in the industry and in the market, which can be a competitive advantage when other companies are searching for interested acquirers. The market will take note of the innovative approach, which might even cause an interest on the part of other companies in adopting the model.

Based on the general outcome of the dissertation thesis and the specific result of the case study, the hypothesis that M\&A success rates and efficiencies could be increased with a new DD concept is supported.

\section{Declaration of Competing Interest}

The authors declare that they have no known competing financial interests or personal relationships that could have appeared to influence the work reported in this paper.

\section{References}

[1] Koch, W. \& Wegmann, J. (2002). Praktiker Handbuch Due Diligence - Analyse mittelständischer Unternehmen "Due Diligence Manual - analysis of mid-size companies". Schäffer-Poeschel, Stuttgart, Germany.

[2] Hauser, H.-E., Kay, R. \& Boerger, S. (2010). Unternehmensnachfolgen in Deutschland 2010 bis 2014 - Schätzung mit weiterentwickeltem Verfahren [Company successions in Germany 2010 to 2014 - Estimation using a further developed method]. Institut für Mittelstandsforschung Bonn: IfM-Materialien, 198.

[3] Lauszus, D., \& Sachs, S. (2019). Market Due Diligence, in: Berens, W., Brauner, H. U., Knauer, T. \& Strauch, J., Due Diligence bei Unternehmensakquisitionen "Due diligence for company acquisitions". Schäffer-Poeschel Verlag, Stuttgart, Germany.

[4] Howson, P. (2017b). The Essentials of M\&A Due Diligence. Routledge, New York, USA.

[5] Largan, C. \& Morris, T. (2019). Qualitative Secondary Research: A Step-By-Step Guide. SAGE Publications, London, England.

[6] Das, T. K. (2019). Managing Trust in Strategic Alliances. Information Age Publishing Inc, Charlotte, USA:

[7] Reed Lajoux, A. (2019). The Art of M\&A, Fifth Edition: A Merger, Acquisition, and Buy-out Guide. Mc Graw-Hill New York, USA. 
[8] Tracy, S. J. (2019). Qualitative Research Methods: Collecting Evidence, Crafting Analysis, Communicating Impact. Wiley and Sons, New Jersey, USA.

[9] Ghosh, S. K. (Ed.). (2020). Circular Economy: Global Perspective. Springer, Kolkata, India. doi:10.1007/978-981-15-1052-6.

[10] Wirtz, B. W. (2003). Mergers \& Acquisitions Management. Gabler, Wiesbaden, Germany.

[11] Coyle, B. (2000). Mergers and Acquisitions. Fitzroy Dearborn Publishers, London, England.

[12] Bruner, R. F. \& Perella, J. R. (2004). Applied Mergers and Acquisitions. Wiley and Sons, New Jersey, USA.

[13] Jansen, S. A. (2016). Mergers \& Acquisitions. Springer, Wiesbaden, Germany.

[14] Gates, S., \& Very, P. (2003). Measuring Performance during M\&A Integration. Long Range Planning, 36(2), $167-185$. doi:10.1016/s0024-6301(03)00004-9.

[15] Koch, W. (2011): Praktiker-Handbuch Due Diligence: Ganzheitliche Analyse und Bewertung von Unternehmen "Due Diligence Manual: Holistic analysis and evaluation of companies”. Schäffer-Poeschel, Stuttgart, Germany.

[16] Giordano, A. D. (2015). Performing Information Governance: A Step-by-step Guide to Making Information Governance Work. IBM Press, Indianapolis, USA.

[17] Russ, W. (2018): Due Diligence, in: Becker, K., Castedello, M. \& Esser, I.: Bewertung und Transaktionsberatung: Betriebswirtschaftliche Bewertungen, Due Diligence, Fairness Opinions "Valuation and transaction advice: business valuation, due diligence, fairness opinions”. IDW Verlag GMBH, Düsseldorf, Germany.

[18] Stern, L. (1993, December). The Crucial Role of Due Diligence. Mortgage Banking, 54(3).

[19] Scott, C. (2013). Due Diligence in der Praxis; Risiken minimieren bei Unternehmenstransaktionen "Due Diligence in practice; Minimize risks in corporate transactions". Gabler, Wiesbaden, Germany. doi:10.1007/978-3-322-94397-2.

[20] Howson, P. (2017a). Due Diligence: The Critical Stage in Mergers and Acquisitions. Gower Publishing, Burlington, USA.

[21] Fuciu, M., \& Dragomir, A. N. (2021). Changes in the Buying Behaviour of the Companies within the Context of the Digital Environment. Scientific Bulletin, 26(2), 138-147. doi:10.2478/bsaft-2021-0016.

[22] Unzeitig, E. \& Kulhavy, H. (2009): Due Diligence im Überblick "Due Diligence an overview", in: Littkemann, J.: Beteiligungscontrolling "Investment Controlling”. NWB, Herne, Germany.

[23] Fernandes, K. J., Raja, V., \& Whalley, A. (2006). Lessons from implementing the balanced scorecard in a small and medium size manufacturing organization. Technovation, 26(5-6), 623-634. doi:10.1016/j.technovation.2005.03.006.

[24] Kaplan, R. S. \& Norton, D. P. (1996). Balanced Scorecard - Translating strategy into action. Harvard Business Press, Boston, USA.

[25] Lehner, S. (2014). Performance Measurement of an Internal Service Team. Grin Verlag, Munich, Germany.

[26] Bauer, F., \& Matzler, K. (2013). Antecedents of M\&A success: The role of strategic complementarity, cultural fit, and degree and speed of integration. Strategic Management Journal, 35(2), 269-291. doi:10.1002/smj.2091.

[27] Rosenbaum, P. R. (2013). Observational Studies. Springer, Philadelphia, USA.

[28] Bogner, A., Littig, B. \& Menz, W. (2009). Interviewing Experts. Palgrave Macmillan, Houndmills, England.

[29] Sutton, R. I. (1997). Crossroads-The Virtues of Closet Qualitative Research. Organization Science, 8(1), 97-106. doi:10.1287/orsc.8.1.97.

[30] Myers, M. D. (2009). Qualitative Research in Business \& Management. SAGE Publications, London, England.

[31] Döring, N. \& Bortz, J. (2016). Forschungsmethoden und Evaluation in den Sozial- und Humanwissenschaften "Research methods and evaluation in the social and human sciences". Springer, Berlin / Heidelberg, Germany.

[32] Mayring, P. (2002). Einführung in die Qualitative Sozialforschung. Eine Anleitung zu qualitativem Denken "Introduction to qualitative research. A guide to qualitative thinking". Beltz, Weinheim, Germany.

[33] Sargeant, J. (2012). Qualitative Research Part II: Participants, Analysis, and Quality Assurance. Journal of Graduate Medical Education, 4(1), 1-3. doi:10.4300/jgme-d-11-00307.1.

[34] Winkler, R. (2013). Corporate Governance als Werttreiber der Due Diligence "Corporate governance as a value driver for Due Diligence”. Verlag Dr. Kovac GmbH - Fachverlag für wissenschaftliche Literatur, Hamburg, Germany.

[35] Kranebitter, G. (2002). Due Diligence - Risikoanalyse im Zuge von Unternehmenstransaktionen "Due diligence - risk analysis in the course of corporate transactions". Verlag Moderne Industrie, Munich, Germnany. 
[36] Voss, I., \& Müller-Stewens, G. (2006). Strategische M\&A-Kompetenz im Rahmen von Akquisitionsstrategien Komponenten, Erfolgsfaktoren und Aufbau. Der M\&A-Prozess, 3-32. doi:10.1007/978-3-8349-9250-5_1.

[37] Farquhar, J. D. (2012). Case Study Research for Business. SAGE Publications, London, England.

[38] Lee, B. \& Saunders, M. N. K. (2017). Conducting Case Study Research for Business and Management Students. SAGE Publications, London, England.

[39] Yin, R. K. (2009). Case study Research. SAGE Publications, London, England. 